\title{
ChemComm
}

\section{Asymmetric synthesis of functionalized cyclohexanes bearing five stereocenters via a one-pot organocatalytic Michael-Michael-1,2-addition sequence $\dagger$}

Cite this: Chem. Commun., 2014, 50,6853

Received 13th March 2014, Accepted 14th May 2014

DOI: $10.1039 / c 4 c c 01885 \mathrm{k}$ www.rsc.org/chemcomm

\author{
Pankaj Chauhan, Gregor Urbanietz, Gerhard Raabe and Dieter Enders*
}

\begin{abstract}
A highly stereoselective one-pot procedure involving an enantioselective Michael addition promoted by low loading of an aminosquaramide catalyst followed by an achiral base catalyzed domino Michael-Knoevenagel-type 1,2-addition sequence provides efficient access to fully substituted cyclohexanes bearing five contiguous stereogenic centers in good yields (68-86\%) and excellent stereoselectivities ( $>30: 1 \mathrm{dr}$ and $96-99 \%$ ee).
\end{abstract}

The asymmetric synthesis of complex molecular structures bearing several different functionalities is one of the major goals of modern synthetic organic chemistry as these structures exist in numerous pharmaceutical and natural products. ${ }^{1}$ The stereocontrolled formation of such complex molecules with several adjacent stereogenic centers is regarded as a great challenge, because with an increase of the stereocenters the number of possible stereoisomers also increases exponentially. Recently, organocatalytic domino or cascade reactions have emerged as a powerful strategy for providing these complex molecular frameworks by employing simple and readily available precursors in a simple operational procedure. ${ }^{2}$ The six-membered carbocycles, i.e. cyclohexane derivatives bearing several adjacent stereogenic centers, are common structural features of many valuable natural products and synthetic bioactive compounds, thus leading to the rapid development of the synthetic strategies for obtaining these structures. ${ }^{3}$

Most of the organocatalytic strategies for the stereoselective synthesis of functionalized cyclohexanes employ aliphatic aldehydes or $\alpha, \beta$-unsaturated analogues as one of the substrates, which are activated by chiral amine catalysts via enamine or iminium ion formation. ${ }^{4}$ The major problem associated with these transformations is the subsequent dehydration after the aldol reaction leading to the loss of two chiral centers. There are only a few reports on the asymmetric synthesis of fully functionalized cyclohexane derivatives.

Institute of Organic Chemistry, RWTH Aachen University, Landoltweg 1,

52074 Aachen, Germany. E-mail: enders@rwth-aachen.de

$\dagger$ Electronic supplementary information (ESI) available. CCDC 990847. For ESI and crystallographic data in CIF or other electronic format see DOI: 10.1039/ c4cc01885k
In 2010 Rodriguez et al. $^{5}$ observed that two molecules of a nitroalkene react in an organocascade asymmetric Michael-MichaelHenry sequence with 1,2-ketoamides to afford fully functionalized cyclohexane derivatives. This process was later on extended by Huang and co-workers ${ }^{6}$ by using 1,2-ketoesters instead of 1,2-ketoamides in the presence of a copper complex of a chiral diamine. Chen and co-workers also succeeded to create as many as six stereogenic centers on spirocyclic oxindoles in one-pot tandem reactions promoted by a chiral secondary amine and achiral amines. ${ }^{7}$ Recently, our group has found that one-pot reactions of $\beta$-ketoesters with two different electrophiles, i.e. nitroalkenes and enals, were facilitated by an amino-thiourea catalyst and a stoichiometric amount of an achiral base to afford fully functionalized cyclohexane derivatives in high stereoselectivities. ${ }^{8}$

It is highly desirable to extend the scope of these one-pot reactions beyond enals and nitroalkenes. Owing to the synthetic challenge of the controlled formation of many stereogenic centers and knowing the advantages associated with organocatalytic onepot cascade reactions as well as the importance of the synthesis of cyclohexane derivatives, we herein disclose unprecedented onepot organocatalytic Michael-Michael-Knoevenagel-type 1,2-addition reactions involving $\beta$-dicarbonyl compounds, nitroalkenes and $\alpha, \alpha$-dicyanoolefins. Employing sequential organocatalysis by using a low loading of a bifunctional amino-squaramide ${ }^{9}$ and a catalytic amount of an achiral base virtually enantiopure cyclohexane derivatives bearing five stereogenic centers with two vicinal tetrasubstituted carbons could be obtained (Scheme 1). To achieve this we have used a chiral amino-squaramide $(1 \mathrm{~mol} \%)$ derived from quinine as catalyst to promote the Michael addition of the $\beta$-ketoester 1a to $\beta$-nitrostyrene (2a) in dichloromethane and after 24 hours the $\alpha, \alpha$-dicyanoolefin $3 \mathbf{a}$ was added followed by the addition of DBU (10 mol\%) in dichloromethane. ${ }^{10}$ Further stirring the reaction for 24 hours afforded the desired cyclohexane 4 a in 53\% yield with 98\% ee and $>30: 1 \mathrm{dr}$ (Table 1, entry 1). The excellent diastereoselectivity of $4 \mathbf{a}$ may be due to a dynamic kinetic resolution of the Michael adduct via base mediated deprotonation of the acidic proton followed by selective protonation (Scheme 1). ${ }^{11}$ Further optimization of the reaction conditions by screening different bases and solvents 


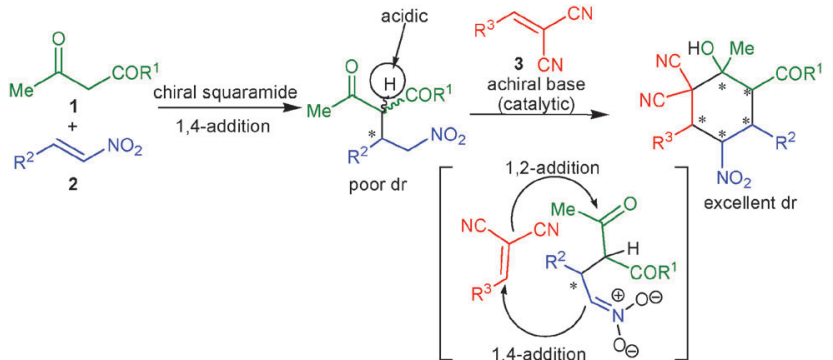

Scheme 1 One-pot Michael-Michael-1,2-addition reaction for the asymmetric synthesis of functionalized cyclohexanes bearing five contiguous stereocenters.

Table 1 Optimizations of reaction conditions ${ }^{a}$

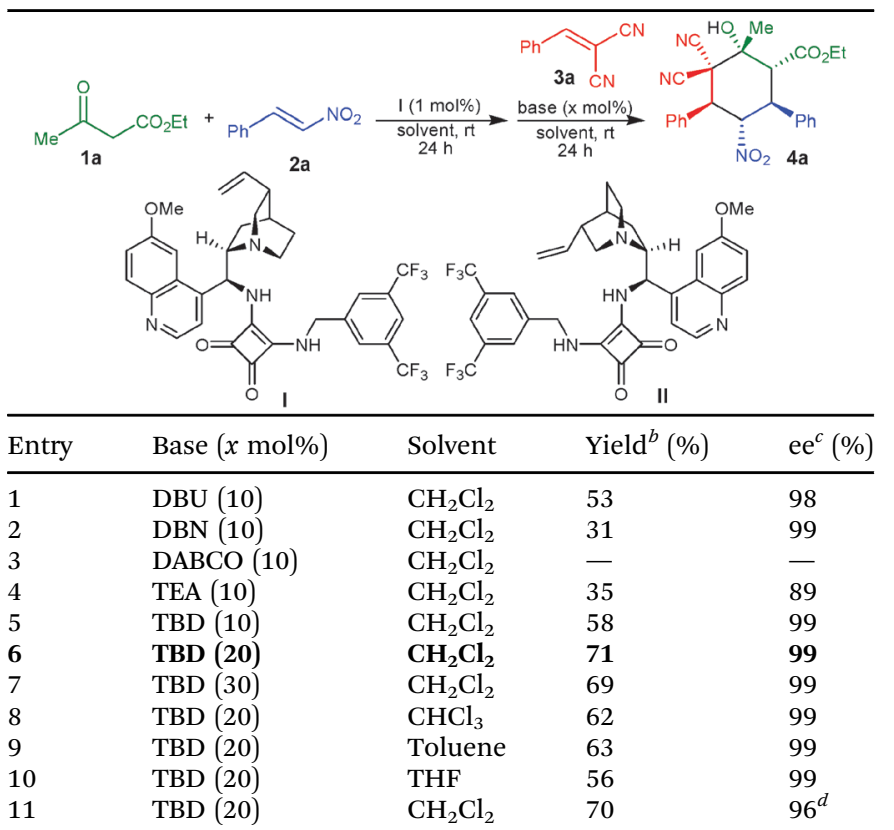

${ }^{a}$ Reaction conditions: $0.2 \mathrm{mmol}$ of $1 \mathrm{a}, 0.2 \mathrm{mmol}$ of $2 \mathrm{a}, 1 \mathrm{~mol} \%$ of $\mathbf{I}$, $0.24 \mathrm{mmol}$ of $3 \mathrm{a}$ and $x \mathrm{~mol} \%$ of base $\left(0.1 \mathrm{M}\right.$ in solvent). ${ }^{b}$ Yield of isolated 4a after column chromatography. ${ }^{c}$ Enantiomeric excess of the major diastereomer $(>30: 1 \mathrm{dr})$ determined by HPLC analysis on a chiral stationary phase. ${ }^{d}$ ee value of ent-4a.

showed that with $20 \mathrm{~mol} \%$ of the guanidine base triazabicyclodecene (TBD) in dichloromethane provides good yields of $71 \%$ and excellent stereoselectivity (entry 6). The use of pseudo-enantiomeric catalyst II leads to the opposite enantiomer of the product in $70 \%$ yield and 96\% ee with excellent diastereoselectivity (entry 11).

Under optimized reaction conditions, the substrate scope was evaluated at $0.5 \mathrm{mmol}$ scale, which revealed that the use of various $\alpha, \alpha$-dicyanoolefins bearing electron withdrawing and electrondonating substituents provides a direct access to the corresponding cyclohexanes $\mathbf{4 b}-\mathbf{g}$ in very good yields (70-84\%) and virtually complete enantioselectivity of $99 \%$ ee (Table 2, entries 2-7). A $\alpha, \alpha$-dicyanoolefin with a heteroaromatic group could be employed under the standard reaction conditions, which afforded the desired product $\mathbf{4 h}$ in $80 \%$ yield and $99 \%$ ee (entry 8 ). However, a $\alpha, \alpha$-dicyanoolefin bearing a cyclohexyl group did not provide
Table 2 Substrate scope ${ }^{a}$

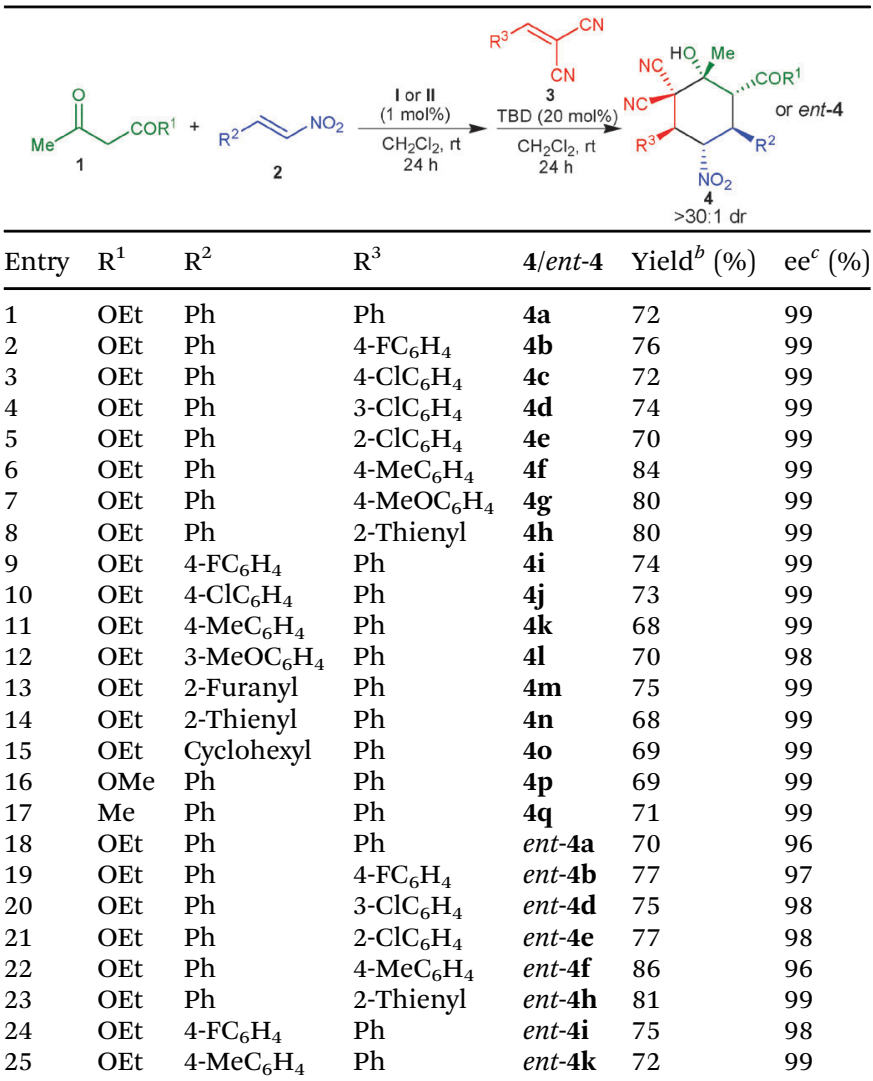

${ }^{a}$ Reaction conditions: $0.5 \mathrm{mmol}$ of $1,0.5 \mathrm{mmol}$ of $2,1 \mathrm{~mol} \%$ of $\mathbf{I}$ (entries 1-17) or II (entries 18-25), $0.6 \mathrm{mmol}$ of 3 and $20 \mathrm{~mol} \%$ of TBD $\left(0.1 \mathrm{M}\right.$ in $\left.\mathrm{CH}_{2} \mathrm{Cl}_{2}\right) .{ }^{b}$ Yield of isolated product after column chromatography. ${ }^{c}$ Enantiomeric excess of the major diastereomer determined by HPLC analysis on a chiral stationary phase.

the desired cyclohexane under the optimized reaction conditions. Further screening of different nitroalkenes showed that various electron rich and electron deficient aromatic nitroalkenes as well as heteroaromatic nitroalkenes also worked well under this one-pot procedure to afford fully functionalized cyclohexanes $4 \mathbf{i}-\mathbf{n}$ in $68-75 \%$ and high stereoselectivities (>30:1 dr and 99\% ee) (entries 9-14). An aliphatic nitroalkene was also tolerated to afford the corresponding adduct 40 in 69\% yield and excellent stereoselectivity (entry 15). Other $\beta$-ketoester and a $\beta$-diketone were also found to react efficiently to give good yields and excellent stereoselectivities of the corresponding products $\mathbf{4 p}$ and $\mathbf{4 q}$ (entries 16 and 17).

The synthesis of the enantiomers of the products is also possible by employing the pseudo-enantiomeric amino-squaramide catalyst II, which afforded the enantiomers of $\mathbf{4 a}, \mathbf{4 b}, \mathbf{4 d}, \mathbf{4 e}, \mathbf{4 f}, \mathbf{4 h}, \mathbf{4 i}$, and $4 \mathbf{k}$ in very good yields (70-86\%) and excellent stereoselectivities ( $>30: 1 \mathrm{dr}$ and 96-99\% ee, entries 18-25).

The absolute configuration of the products $4 \mathbf{4}-\mathbf{q}$ synthesized by squaramide I was assigned as $1 S, 2 S, 3 R, 4 R$ and $6 S$ on the basis of a X-ray crystallographic analysis of $4 a$ (Fig. 1). ${ }^{12}$

Further we have tried to extend the substrate scope of this one-pot methodology by employing olefin 5 , which gave the adduct 6 bearing six contiguous stereocenters in $67 \%$ yield and 99\% ee, albeit low diastereoselectivity (Scheme 2). 


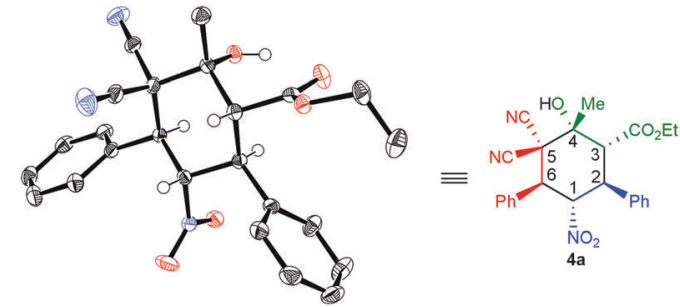

Fig. $1 X$-ray structure of $4 \mathrm{a}[\mathrm{Cu}-\mathrm{K} \alpha$ radiation $(\lambda=1.54178 \AA$ ),$T=120 \mathrm{~K}$, Flack parameter: $\chi=0.025(115)]$.

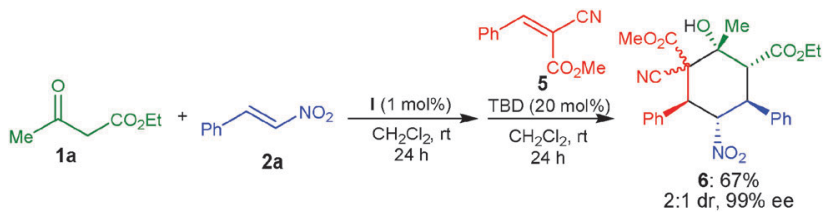

Scheme 2 One-pot organocatalytic Michael-Michael-1,2-addition reaction between $1 \mathrm{a}, 2 \mathrm{a}$ and $\mathbf{5}$.

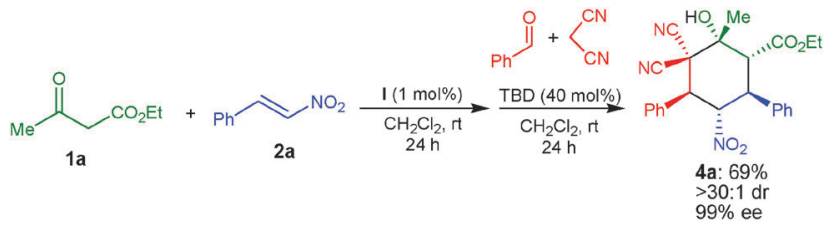

Scheme 3 One-pot stereoselective organocatalytic Michael-Knoevenagel condensation-Michael-1,2-addition reaction.

A one-pot reaction involving the in situ formation of the $\alpha, \alpha$-dicyanoolefin was successfully performed, which involves the addition of benzaldehyde and malononitrile followed by TBD (40 mol\%) to the initially formed Michael adduct of 1a with 2 a catalyzed by I (Scheme 3). The corresponding product 4a was obtained in 69\% yield, >30:1 dr and 99\% ee through this one-pot Michael-Knoevenagel condensation-Michael-1,2addition sequence.

A successful gram-scale reaction between 1a, 2a and 3a to form 4a showed that the reaction efficiency was maintained, thus highlighting the practical and preparative utility of this one-pot process (Scheme 4).

In conclusion, we have demonstrated the application of a one-pot sequential organocatalysis for the asymmetric synthesis of functionalized cyclohexanes. A low loading of a chiral organocatalyst and a low cost commercially available achiral base afford

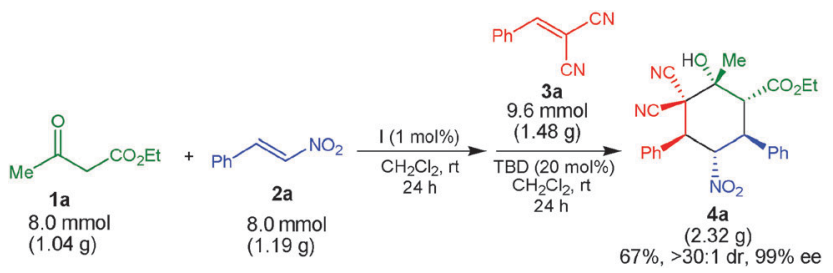

Scheme 4 Gram-scale one-pot stereoselective organocatalytic MichaelMichael-1,2-addition reaction. a series of highly substituted cyclohexane derivatives via one-pot Michael-Michael-1,2-addition reactions in very good yields and excellent stereoselectivities. The enantiomers of the multifunctionalized cyclohexanes are easily accessible by employing a pseudoenantiomeric amino-squaramide catalyst. This method can be scaled up without any loss of reaction efficiency.

Support from the European Research Council (ERC Advanced Grant "DOMINOCAT") is gratefully acknowledged.

\section{Notes and references}

1 For reviews, see: (a) K. C. Nicolaou, T. Montagnon and S. A. Snyder, Chem. Commun., 2003, 551; (b) K. C. Nicolaou, D. J. Edmonds and P. G. Bulger, Angew. Chem., Int. Ed., 2006, 45, 7134.

2 For selected reviews on organocatalytic domino-cascade reactions, see: (a) D. Enders, C. Grondal and M. R. M. Hüttl, Angew. Chem., Int. Ed., 2007, 46, 1570; (b) X. Yu and W. Wang, Org. Biomol. Chem., 2008, 6, 2037; (c) C. Grondal, M. Jeanty and D. Enders, Nat. Chem., 2010, 2, 167; (d) Ł. Albrecht, H. Jiang and K. A. Jørgensen, Angew. Chem., Int. Ed., 2011, 50, 8492; (e) A. Grossmann and D. Enders, Angew. Chem., Int. Ed., 2012, 51, 314; $(f)$ H. Pellissier, Adv. Synth. Catal., 2012, 354, 237; $(g)$ P. Chauhan and D. Enders, Angew. Chem., Int. Ed., $2014,53,1485$.

3 For reviews on carbocycles, see: (a) C. Cismas, A. Terec, S. Mager and I. Grosu, Curr. Org. Chem., 2005, 9, 1287; (b) J. Wolfling, ARKIVOC, 2007, 5, 210; (c) A. M. Shestopalov, A. A. Shestopalov and L. A. Rodinovskaya, Synthesis, 2008, 1; (d) J. Shen and C.-H. Tan, Org. Biomol. Chem., 2008, 6, 3229; (e) S. Reymond and J. Cossy, Chem. Rev., 2008, 108, 5359; $(f)$ S. Goudedranche, W. Raimondi, X. Bugaut, T. Constantieux, D. Bonne and J. Rodriguez, Synthesis, 2013, 1909.

4 (a) D. Enders, M. R. M. Hüttl, Y. Runsink, G. Raabe and B. Wendt, Angew. Chem., Int. Ed., 2007, 46, 467; (b) D. Enders, M. R. M. Hüttl, G. Raabe and J. W. Bats, Adv. Synth. Catal., 2008, 350, 267; (c) P. G. McGarraugh and S. E. Brenner, Org. Lett., 2009, 11, 5654; (d) Y. Wang, R.-G. Han, Y.-L. Zhao, S. Yang, P.-F. Xu and D. J. Dixon, Angew. Chem., Int. Ed., 2009, 48, 9834; (e) D. Enders, B. Schmid and N. Erdmann, Synthesis, 2010, 2271; $(f)$ M. Rueping, K. L. Haack, W. Ieawsuwan, H. Sundén, M. Blanco and F. R. Schoepke, Chem. Commun., 2011, 47, 3828; $(\mathrm{g}$ ) C. Cassani, X. Tian, E. C. EscuderoAdán and P. Melchiorre, Chem. Commun., 2011, 47, 233; (h) A. Zea, A.-N. R. Alba, A. Mazzanti, A. Moyano and R. Rios, Org. Biomol. Chem., 2011, 9, 6519; (i) D. Enders, A. Greb, K. Deckers, P. Selig and C. Merkens, Chem. - Eur. J., 2012, 18, 10226; $(j)$ X. Zeng, Q. Ni, G. Raabe and D. Enders, Angew. Chem., Int. Ed., 2013, 52, 2977.

5 (a) O. Baslé, W. Raimondi, M. M. Sanchez Duque, D. Bonne, T. Constantieux and J. Rodriguez, Org. Lett., 2010, 12, 5246; (b) W. Raimondi, M. M. Sanchez Duque, S. Goudedranche, A. Quintard, T. Constantieux, X. Bugaut, D. Bonne and J. Rodriguez, Synthesis, 2013, 1659.

6 D. Shi, Y. Xie, H. Zhou, C. Xia and H. Huang, Angew. Chem., Int. Ed., 2012, 51, 1248.

7 K. Jiang, Z.-J. Jia, S. Chen, L. Wu and Y.-C. Chen, Chem. - Eur. J., 2010, 16, 2852.

8 D. Enders, G. Urbanietz, E. Cassens-Sasse, S. Keeß and G. Raabe, Adv. Synth. Catal., 2012, 354, 1481.

9 For reviews on squaramides, see: (a) J. Alemán, A. Parra, H. Jiang and K. A. Jørgensen, Chem. - Eur. J., 2011, 17, 6890; (b) R. I. Storer, C. Aciro and L. H. Jones, Chem. Soc. Rev., 2011, 40, 2330; for examples, see: (c) J. P. Malerich, K. Hagihara and V. H. Rawal, J. Am. Chem. Soc., 2008, 130, 14416; (d) H. Y. Bae, S. Some, J. S. Oh, Y. S. Lee and C. E. Song, Chem. Commun., 2011, 47, 9621; (e) Y.-F. Wang, R.-X. Chen, K. Wang, B.-B. Zhang, Z.-B. Lib and D.-Q. Xu, Green Chem., 2012, 14, 893; $(f)$ C. C. J. Loh, D. Hack and D. Enders, Chem. Commun., 2013, 49, 10230.

10 For the initial optimization, see ESI $\dagger$.

11 For a review on organocatalytic DKR, see: $(a)$ H. Pellissier, $A d v$. Synth. Catal., 2011, 353, 659; for recent examples, see: (b) T. Cheng, S. Meng and Y. Huang, Org. Lett., 2013, 15, 1958; (c) M. BergeronBrlek, T. Teoh and R. Britton, Org. Lett., 2013, 15, 3554; (d) Q. Dai, H. Arman and J. C.-G. Zhao, Chem. - Eur. J., 2013, 19, 1666.

12 CCDC 990847 (for 4a). 